\title{
0 meio ambiente do trabalho como instrumento de proteção ao trabalhador
}

\section{Vital José Pessoa Madruga Filho',*, Helder Formiga Fernandes ${ }^{1}$, Antônio Waldir Bezerra Cavalcanti Neto ${ }^{2}$, Paulo Joviniano Álvares dos Prazeres ${ }^{3}$}

${ }^{1}$ Universidade Federal da Paraíba. Centro de Ciências Exatas e da Natureza. Programa de Pós-Graduação em Desenvolvimento e Meio Ambiente. Campus I. João Pessoa-PB, Brasil (CEP 58051-900).*E-mail: vitalpessoa@bol.com.br.

${ }^{2}$ Tribunal de Justiça da Paraíba. Praça João Pessoa, S/№. Centro. João Pessoa-PB, Brasil (CEP 58013-902).

${ }^{3}$ Ordem dos Advogados do Brasil. Subseção Olinda. Avenida Presidente Kennedy, 1.001. Peixinhos. Olinda-PE, Brasil (CEP 53230-630).

Resumo. 0 presente estudo tem como objetivo geral analisar o meio ambiente do trabalho, que deve ser compreendido como sendo aquele que enfatiza e tutela a segurança do obreiro no seu ambiente laboral, e objetivo específico analisar a harmonia com o princípio constitucional da dignidade humana, visando a garantir a segurança do trabalhador, a exemplo do direito à saúde, prevenção de acidentes, salubridade e condições de exercício saudável do trabalho. Para a realização da presente investigação foi necessário aplicar o método dogmático, como a hermenêutica dos textos normativos recomenda, mas também o aporte à doutrina e à transversalidade foram necessários, desde que se trata de tema interdisciplinar de elevado teor político e sociológico, tudo alinhavado por uma tradição de pensamento racionalista igualitária.

Palavras-chave: Meio ambiente; Trabalho; Segurança; Saúde.

\begin{abstract}
The environment of work as an instrument of worker protection. The present study aims to analyze the work environment, which must be understood as one that emphasizes and protects the safety of the worker in his or her working environment, and specific objective to analyze the harmony with the constitutional principle of human dignity, aiming at guaranteeing worker safety, such as the right to health, accidents prevention, salubrity and healthy working conditions. For the accomplishment of the present investigation it was necessary to apply the dogmatic method, as the hermeneutics of normative texts recommends, but also the contribution to doctrine and transversality were necessary, since it is an interdisciplinary subject of high political and sociological content, all based on a tradition of egalitarian rationalist thinking.
\end{abstract}

Keywords: Environment; Work; Safety; Health.
Recebido: 06/08/2018

Aceito:

$27 / 08 / 2018$

Publicado: 31/08/2018

Acesso aberto

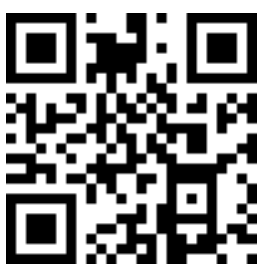

ORCID

(1) 0000-0002-0351-9807 Vital José Pessoa Madruga Filho

(1) 0000-0002-0370-0673

Hélder Formiga

Fernandes

(1) 0000-0002-2834-9154

Antônio Waldir

Bezerra Cavalcanti

Neto

(1) 0000-0002-5418-8155

Paulo Joviniano

Álvares dos Prazeres 


\section{Introdução}

0 meio ambiente, para efeitos didáticos, está dividido em quatro elementos, o natural, o cultural, o artificial e o do trabalho (Trennepohl, 2007). 0 presente estudo tem como objetivo abordar o quarto elemento classificatório, o meio ambiente do trabalho, que deve ser compreendido como sendo aquele que enfatiza e tutela a segurança do homem no seu local de trabalho (Figueiredo e Gondim, 2015).

Nesta perspectiva, o conjunto normativo que tutela o trabalhador, em harmonia com o princípio constitucional da dignidade humana, prevê uma gama de normas que visam a garantir a segurança, a saúde do trabalhador, a prevenção de acidentes, a salubridade e as condições de exercício saudável do trabalho.

Contudo, apesar de ser considerado um direito fundamental, o direito ao meio ambiente do trabalho é aviltado de forma sistemática e contumaz, contando com uma tímida fiscalização dos órgãos protetivos do trabalho, o que prejudica a eficácia da norma em proveito do trabalhador (Figueiredo e Gondim, 2015).

Deste modo, do presente artigo, serão auferidas abordagens à legislação em vigor, que tratam sobre as medidas de proteção deferidas aos trabalhadores, de ordem cogente, as quais são aderidas aos contratos de trabalho, cuja finalidade é a prevenção contra acidentes e doenças oriundas do ambiente próprio laboral, cujo acometimento poderá comprometer a saúde do trabalhador.

A imprescindibilidade do tema reside no fato de que a vida é bem jurídico de elevada guarida no ordenamento jurídico brasileiro, de modo que a empresa empregadora, deverá oferecer aos seus trabalhadores, um ambiente saudável, e sobretudo, dotado de segurança aos seus colaboradores.

Diante dessa circunstância, faz-se mister elevar o nível de fiscalização dos órgãos protetivos, para assegurar a aplicabilidade da norma trabalhista, na esperança de garantir condições dignas aos trabalhadores, a partir de um meio ambiente do trabalho seguro e propício à observância e acolhimento do princípio da dignidade da pessoa humana.

Desta forma, a valorização da dignidade do trabalhador, que deve ser compreendida como a parte mais vulnerável da relação laboral, necessita de tutela legal e supervisão protetiva por parte dos órgãos de proteção trabalhista, como forma de mitigar a ocorrência de acidentes no ambiente de trabalho, a proliferação de patologias inerentes à condição de trabalho, além de evitar desgastes físicos e emocionais.

\section{Do breve escorço histórico sobre o conceito de meio ambiente do trabalho}

A definição contemporânea de meio ambiente do trabalho possui marco cronológico bastante recente, exsurgindo em meados do século XX. Todavia, a preocupação para com a saúde e a segurança do trabalhador, como esfera distinta da saúde pública, foi evidenciada apenas com a Revolução Industrial do século XVIII, em razão da larga escala de produção industrial e o surgimento das sociedades de massa, o que fez desencadeou uma observância maior acerca da preservação ambiental (Santos, 2016).

No período da Revolução Industrial, segundo Durkheim (1964), as pessoas que foram excluídas da nova divisão internacional do trabalho, acabaram sendo colocadas às margens da ordem de social e de produção laboral. Marx destaca os efeitos "alienantes" dos métodos e atividades diante da exaustão e repetição da mesma atividade para qualquer trabalhador. Engels, por outro lado, intensifica o fato de que muitos trabalhadores, que antes tinha boa saúde laboral, diante das práticas inadequadas de trabalho, acabariam por sofrer de uma 
série de lesões ao tornarem-se vítimas de algum acidente e, por exemplo, ficarem "aleijadas" (Engels, 1969). Porém, ambos não fizeram nenhuma discussão sobre as consequências jurídicas desses "acidentes de trabalho", ficando restrito aos temas de "população excedentária" ou "exército de reserva de mão-de-obra" (Marx, 1981).

A partir deste contexto histórico, surgiu-se o ramo da Medicina do Trabalho, capaz de garantir proteção à saúde e segurança do trabalhador, idealizada pelo médico italiano Bernardino Ramazzini, com a publicação do livro "As doenças Ocupacionais dos Trabalhadores", no ano de 1700 (Santos, 2016).

Neste interim, para Prata (2016), com a eclosão do constitucionalismo social, que passou a elencar normas relativas a proteção à saúde e segurança do trabalhador, elevando tal premissa a nível constitucional, observa-se que o tema começou a ganhar azo normativo no início do século $\mathrm{XX}$, de sorte que a própria Constituição Mexicana de 1917, previu em favor do trabalhador, normas protecionistas, capazes de determinar a obrigatoriedade de toda empresa proporcionar habitações cômodas e higiênicas, a adoção de medidas de higiene, saúde, segurança e de prevenção de acidentes, escolas e serviços de enfermagem aos trabalhadores, a indenização por acidentes do trabalho, enfim, documentos constitucionais que sentiram a necessidade de preservar com maior higidez a proteção à saúde do trabalhador.

O Brasil, ainda sem elevar o tema a nível constitucional, editou o Decreto Legislativo $\mathrm{n}$ - 3.274, de 15 de janeiro de 1919, quando prenunciou seu marco normativo na proteção à saúde e segurança dos trabalhadores.

\section{0 meio ambiente do trabalho e os Direitos Humanos}

De acordo com 0 art. 1으, da Declaração Universal dos Direitos
Humanos da ONU, giza-se que "Todos os seres humanos nascem livres e iguais em dignidade e em direitos. Dotados de razão e de consciência, devem agir uns para com os outros em espírito de fraternidade".

Discorrendo sobre o princípio da dignidade da pessoa humana, Moraes (1997, p. 60-61) informa que:

[...] o princípio fundamental consagrado pela Constituição Federal da dignidade apresenta-se em uma dupla concepção. Primeiramente, prevê um direito individual protetivo, seja em relação ao próprio estado, seja em relação aos demais indivíduos. Em segundo lugar, estabelece verdadeiro dever fundamental, de tratamento igualitário dos próprios semelhantes... a princípio do direito romano: honeste vivere (viver honestamente), alterum non laedere (não prejudique ninguém) e suum cuique tribuere (dê a cada um o que lhe é devido) (Moraes, 1997, p. 6061).

Penteado Filho (2008), tratando sobre os direitos sociais, salienta que "é bom que se diga que os direitos sociais podem ser conceituados como direitos fundamentais (liberdades positivas) que visam à melhoria da qualidade de vida dos hipossuficientes" (Penteado FILHO, 2008, p. 83).

No emblemático conceito importado por Santos (1997), os direitos humanos são:

[...] enquanto forem concebidos como direitos humanos universais, os direitos humanos tenderão a operar como localismo globalizado uma forma de globalização de-cimapara-baixo. Serão sempre um instrumento do "choque de civilizações" tal como o concebe Samuel Huntington (1993), ou seja, como arma do Ocidente contra o resto do mundo ("the West against the rest") (Santos, 1997, p. 18).

Ainda segundo Santos (1997), localismo globalizado: 
Consiste no processo pelo qual determinado fenômeno local é globalizado com sucesso, seja a atividade mundial das multinacionais, a transformação da língua inglesa em língua franca, a globalização do fast food americano ou da sua música popular ou a adoção mundial das leis de propriedade intelectual ou de telecomunicações dos EUA (Santos, 1997, p. 15).

Deste modo, é inconteste que o meio ambiente, aliado às relações de trabalho, inserem-se na plataforma de estudos e de tutela positiva no contexto dos direitos humanos.

\section{o Princípio da Proteção ao Trabalhador no contexto do meio ambiente do trabalho}

Pelo princípio da proteção ao trabalhador, tem-se o fundamento basilar que sustenta o Direito do Trabalho, cujo escopo visa a tutelar os interesses da parte hipossuficiente, no caso, o trabalhador, como forma de assegurar o equilíbrio da relação jurídico-trabalhista (Brandão, 2016).

Nesta senda, o meio ambiente do trabalho deve ser entendido como a ambiência pela qual o trabalhador está inserido no exercício habitual do seu labor, de sorte que a proteção ao meio ambiente do trabalho, reflete um enaltecimento do princípio da proteção do trabalhador, representando um interesse coletivo como síntese de interesses individuais, de modo que a ofensa de um indivíduo, representa afronta a toda coletividade, tendo em vista que o meio ambiente possui tutela difusa.

Assim, para ratificar e acrescer o tema, Santos (2016) pontua da seguinte forma:

Em suma conceitual, o meio ambiente do trabalho consiste no conjunto de condições físicas, químicas, biológicas, interpessoais e psíquico-mentais, naturais e artificiais, móveis e imóveis, internas e externas, cujos elementos, leis e interações abrigam, influenciam e regem a vida das pessoas e as suas atividades no local de trabalho, independentemente do seu estatuto jurídico e das suas condições pessoais, cujo equilíbrio é essencial à sadia qualidade de vida, à incolumidade físico-psíquica e à capacidade laboral dos indivíduos de que dele participam (Santos, 2016, p. 226).

Os direitos fundamentais são bidimensionais, por conta de duas grandezas, uma jurídico-positiva e outra jurídico-subjetiva, as dimensões positivas tem por partida a continuação saudável e cumprimento dos direitos fundamentais, já as dimensões negativas tem como objetivo proteger e rodear a ordem jurídica do indivíduo. (Canotilho, 2008).

\section{Proteção constitucional ao meio ambiente do trabalho e sua prevalência como direito fundamental}

Com a Declaração Universal dos Direitos Humanos, preconizou-se em seu art. 23, $\S 1^{\circ}$, que "toda pessoa tem direito ao trabalho, à livre escolha de emprego, a condições justas e favoráveis de trabalho e à proteção contra o desemprego". Ao concatenar tal ideia à consciência ambiental, é preciso mencionar o Tratado de Roma, em 1957, que criou a Comunidade Econômica Europeia (CEE), que alavancou o marco para a proteção ao meio ambiente ecologicamente equilibrado (Brandão, 2016).

No ano de 1972, ocorreu a Conferência de Estocolmo sobre Meio Ambiente Humano, capitaneada pelas Nações Unidas, quando, lamentavelmente, o Brasil e a China não reconheceram a verdadeira dimensão do problema. De qualquer sorte, ali foi promulgado o primeiro documento no 
qual é expresso que o meio ambiente é um direito humano (Prata, 2016).

Nesse mesmo contexto histórico, a Organização Internacional do Trabalho passou a enfatizar com maior destaque aspectos atinentes ao meio ambiente do trabalho, em detrimento de uma política normativa focada apenas em medidas profiláticas acerca da saúde e segurança dos trabalhadores. Assim, por ocasião do advento da Convenção no 148 da OIT (1977), que trata da contaminação do ar, do ruído e de vibrações, e da Convenção no 155 da OIT (1981), que prevê normas e princípios sobre a saúde, a segurança e a saúde e o meio ambiente do trabalho. É de se suscitar a importância da Conferência Mundial da OIT sobre Emprego, Distribuição de Renda e Progresso Social, realizada em Genebra, no ano de 1976, que traz consigo o início da consciência a respeito da necessidade de proteção do trabalhador diante do neoliberalismo, cuja corrente ideológica já demonstrava sinais de ataques aos direitos dos trabalhadores (Santos, 2016).

Com efeito, o meio ambiente do trabalho deve ser compreendido sob uma dimensão abrangente, em detrimento da antiga visão reducionista, que minimizava o tema ao caráter meramente científico no que tange a Medicina e a Segurança do Trabalho. Assim, é possível albergar dentro de tal conceito, as demandas biológicas do trabalhador, além das suas necessidades sociais e psíquicas (Trennepohl, 2007).

Portanto, é mister asseverar que "a busca pela redução dos riscos para à saúde, no ambiente laboral, é anterior à promulgação da Constituição de 1988" (Stümer, 2014).

Assim, essa ampliação teleológica do conceito de meio ambiente do trabalho, por deveras ampliada, deve ser interpretada através da inteligência do art. 225, da Constituição Federal, que apregoa o direito de todos o acesso ao meio ambiente ecologicamente equilibrado (Brandão, 2016).
Nesta perspectiva, o STF já ponderou ser o meio ambiente do trabalho como um direito fundamental de terceira dimensão, calcado no princípio da solidariedade integracional e no princípio do desenvolvimento sustentável, como forma de se garantir o “... justo equilíbrio entre as exigências da economia e da ecologia..." (V. ADI 3540 MC, Relator: Min. Celso de Mello, Tribunal Pleno, julgado em 10.9.2005, DJ 3.2.2006 p.14 Ementa v. 2219-03 p. 528).

Diante da flagrante categorização do meio ambiente do trabalho como direito fundamental, a proteção a tal ambiência se afigura como um direito irrenunciável, inalienável e imprescritível.

Neste sentir, a Constituição Federal de 1988 contemplou várias disposições que se relacionam com a questão do meio ambiente do trabalho, in verbis:

Art. 1ㅇ A República Federativa do Brasil [...] tem como fundamentos:

[...]

II - a cidadania;

III - a dignidade da pessoa humana;

IV - os valores sociais do trabalho e da livre-iniciativa...

Já no seu Título II - Dos direitos e garantias fundamentais, Capítulo II - Dos direitos sociais -, temos:

Art. 5o Todos são iguais perante a lei, sem distinção de qualquer natureza, garantindo-se aos brasileiros e aos estrangeiros residentes no país a inviolabilidade do direito à vida, à liberdade, à igualdade, à segurança e à propriedade.

E ainda outros direitos trabalhistas relacionados ao ambiente organizacional, in verbis:

Art. 70 São direitos dos trabalhadores urbanos e rurais, além de outros que visem à melhoria de sua condição social: 
[...]

XXII - redução dos riscos inerentes ao trabalho, por meio de normas de saúde, higiene e segurança;

XXIII - adicional de remuneração para as atividades penosas, insalubres ou perigosas, na forma da lei;

$[\ldots]$

XXVIII - seguro contra acidentes de trabalho, a cargo do empregador, sem excluir a indenização a que este está obrigado, quando incorrer em dolo ou culpa;

[...].

Ora, o art. 7ํ da Constituição da República, na forma supra transcrita, finca na condição de direito dos trabalhadores urbanos e rurais a mitigação dos riscos inerentes ao trabalho, através de normas que promovam a saúde, higiene e segurança do ambiente de trabalho.

Nesse toar, apesar de não integrar o rol expresso dos direitos consagrados na Constituição Federal, o direito ao meio ambiente do trabalho e à qualidade de vida é uma autêntica demonstração de direito fundamental coletivo, na perspectiva do art. $5^{\circ}$, $\S 2^{\circ}$, da Constituição Federal, quando estabelece que "Os direitos e garantias expressos nesta Constituição não excluem outros decorrentes do regime e dos princípios por ela adotados, ou dos tratados internacionais em que a República Federativa do Brasil seja parte".

Nesta perspectiva, o art. 200, inciso VIII, do texto constitucional, infere que, "ao Sistema Único de Saúde, compete, além de outras atribuições, nos termos da lei, colaborar na proteção do meio ambiente, nele compreendido o do trabalho".

A Declaração Universal dos Direitos Humanos de 1948 trouxe, de forma direta, o direito à saúde no artigo XXV. Em 1966, o Pacto Internacional sobre Direitos Econômicos, Sociais e Culturais inova, em não só reconhecer o direito à saúde da Declaração de 1948, quando, também, traz os mecanismos que os Estados devem implementar para garantir os direitos à saúde, como ações preventivas e curativas (Trigueiro, 2017).

No Brasil, o direito à saúde só veio a ser constitucionalmente assegurado em 1988, genericamente no art. 6o e com detalhes nos arts. 196 a 200. A Constituição afirma que a saúde é direito de todos, então ela consagra o direito à saúde das pessoas com deficiência. A Constituição, também, destaca o papel do Sistema Único de Saúde (Trigueiro, 2017).

A organização e os parâmetros dos trabalhos do Sistema Único de Saúde estão disciplinados na Lei Orgânica da Saúde, Lei no 8.080/1990. Onde a Lei no $8.142 / 1990$, disciplinando a forma de participação da sociedade na gestão do Sistema Único de Saúde e sobre as transferências intergovernamentais de recursos dos entes políticos federados, União, estados e municípios (Trigueiro, 2017).

A Constituição da Organização Mundial de Saúde (OMS/WHO/1946, elaborada na cidade de Nova Iorque, em 22 de julho de 1946) diz que o direito à saúde tem uma dimensão social, eliminando o binômio saúde-doença, princípio básico da felicidade e harmonia (Trigueiro, 2017).

Leal (2008) defende o direito à saúde como umas das dimensões do mínimo existencial à dignidade da pessoa humana.

Assim, é mister suscitar que o meio ambiente do trabalho adequado e seguro é de fundamental importância à implementação dos direitos do cidadão trabalhador, cuja inobservância, agride toda a sociedade que custeia a Previdência Social, que ao final, é quem adimple todo prejuízo pela inobservância às normas de saúde e segurança do empregado, além do que o ponto nodal da proteção deferida ao meio ambiente do trabalho é saúde e o bem estar do trabalhador (Melo, 2007). 
Para Gomes (2005, p. 326), o bem supremo da vida é a saúde: "condições de maior eficiência produtiva do homem". Modernamente, a saúde passou a ter valor mais positivo, mais estável, menos extra-humano, valor econômico:

Cumpre, mais do que a qualquer outro, dar ao mutilado do trabalho os meios para, pelo trabalho, obter o necessário para seu sustento. Cumpre restituir-lhe o valor como unidade econômica, habilitando-se a produzir e a consumir. Cumpre desviá-lo da inatividade e do ócio, geradores da instabilidade e do vicio (Gomes, 2005, p. 326).

Para Pereira (2009) o problema da prevenção dos acidentes do trabalho que:

[...] moral e socialmente, o problema é também digno de maior atenção, pois são muitos milhões de operários que ficam inutilizados ou que se mantém enfermos. É, pois, lógico que o estudo de tudo quanto tente diminuir, já que eliminar os acidentes é impossível, portanto prevenir e evitar, seja considerado de máximo interesse pelos médicos, psicólogos e engenheiros, com o fim de organizar a prevenção dos acidentes e ver se alcançam a possibilidade de poder determinar a predisposição ao acidente" (Araujo Junior, 2009, p. 70).

Para fazer esteio ao inciso XXVIII, do art. 7으, da Carta Republicana, o acidente de trabalho enseja a responsabilidade civil do empregador, a depender do caso, além dos inevitáveis desdobramentos previdenciários inerentes à problemática laboral (Jorge Neto e Cavalcante, 2004).

Ademais, no que pertine a dignidade humana, um ambiente de trabalho em que se constata a presença e exploração da mão de obra infantil ou até mesmo o trabalho em condição análoga à escravidão, por exemplo, significa uma afronta aos direitos universais do homem e, por conseguinte, atinge a toda humanidade e não apenas àqueles trabalhadores diretamente explorados. Ressalte-se ainda que, a dignidade humana ainda é aviltada pela prática contumaz e reiterada de atos de assédio moral ou sexual no trabalho (OIT, 2010).

No Brasil, os institutos de segurança, engenharia, higiene e saúde do trabalho estão preconizados no art. 154 e seguintes da CLT. Dessa forma, a legislação atribuiu ao Ministério do Trabalho, a competência para firmar as políticas relativas a normatização do trato relativo à saúde e segurança do trabalhador. Tais instrumentos legais são de imperiosa preciosidade para a disciplina da segurança do trabalho, haja vista que elenca as normas protetivas ao trabalhador (Proscurcin, 2015).

\section{Segurança e saúde no ambiente de trabalho}

Ao empregado, deve-se a garantia a um ambiente de trabalho minimamente seguro, com ferramentas, máquinas, produtos que são utilizados, incluindo o meio físico sobre o qual o empregado está inserido, devem apresentar as melhores condições técnicas (Brandão, 2016).

0 direito à saúde está intimamente relacionado com o direito à vida, constituindo ambos na qualidade de direito fundamental, de sorte que seria controversa, a possibilidade do trabalho por em risco tais bens, que são inalienáveis no prisma do ordenamento jurídico pátrio. 0 mínimo que se pode esperar de um ambiente de trabalho, é que o trabalhador volte incólume, física e psicologicamente, para casa e para sua família (Figueiredo e Gondim, 2015).

Ressalte-se que os adicionais de periculosidade e de insalubridade, não são capazes de isentar o empregador de adotar medidas para pôr termo às condições impróprias de trabalho, que afetam diametralmente a saúde das pessoas que ali trabalham (Proscurcin, 2015). 
É preciso considerar que a vida humana não tem preço, e a sua perda representa uma lástima irreversível para a sociedade, com base em seu núcleo familiar, que deve ser preservada de situações tão maléficas, muitas vezes pelo fato irresponsável de certos indivíduos resistirem a adoção de medidas protetivas à saúde e segurança dos trabalhadores.

Consoante dicção do art. 168 da CLT, resta a obrigatoriedade de realização de exame médico, as expensas do empregador, o qual deve ser realizado no momento da admissão, na dispensa, e em periodicidade enquanto perdurar a vigência do contrato de trabalho do trabalhador (Sturme, 2016).

Assim, eventual acometimento de patologia profissional ou ocorrência de acidente de trabalho, deverão ser imediatamente notificadas através da CAT, na forma preconizada pelo art. 169, da CLT (Sturme, 2016).

Apesar de toda essa exigência legal, o exame médico previsto no art. 168 do diploma obreiro, sofre deficiências na realidade fática, uma vez que sua submissão muitas vezes é feita através de "entrevistas", do qual prescinde-se de um efetivo exame clínico, capaz de demonstrar eventuais patologias acometidas em momento anterior ao contrato de trabalho (exame admissional), bem como no transcurso da sua vigência (exames periódicos ou demissional), o que seguramente importará em prejuízos ao trabalhador, principalmente na hipótese de acometimento de doenças no decorrer do contrato de trabalho (Stümer, 2016).

\section{Mecanismos de proteção à saúde e segurança no ambiente de trabalho}

No Brasil, o ordenamento jurídico pátrio fez exsurgir alguns programas que visam a mitigar mortes e acidentes decorrentes de eventuais falhas existentes nas relações de trabalho, com reflexos no próprio ambiente laboral.

\section{Programa de Prevenção de Riscos Ambientais (PPRA)}

No intuito de colaborar com o meio ambiente ecologicamente equilibrado, o PPRA traz para a empresa a responsabilidade à preservação da saúde e segurança do trabalhador, com fundamento na NR-9. O Programa reconhece os riscos presentes e futuros existentes no próprio ambiente de trabalho, e elabora uma proposta de proteção ao trabalhador, bem como aos recursos naturais. Certo é que o programa visa extinguir todas as situações que ponham em risco à segurança, visando a proteção das pessoas e dos recursos naturais e, enfim, à sadia qualidade de vida preconizada pela Constituição Federal (Proscurcin, 2015).

\section{Serviços Especializados em Engenharias de Segurança e Medicina do Trabalho (SESMT)}

Trata-se de um instrumento, com azo na NR-4, que obriga as empresas privadas ou públicas a implementar o SESMT, caso as empresas detenham mais de $50 \%$ de seus empregados em atividades em grau de risco maior ao da atividade básica. Para Proscurcin (2015, p. 343):

0 pessoal especializado e com dedicação exclusiva para esses serviços é o seguinte: engenheiro de Segurança, médico do Trabalho, enfermeiro do Trabalho, auxiliar de Enfermagem e técnico de Segurança. Suas atividades estão desenhadas na NR: aplicar os conhecimentos para a solução dos problemas do ambiente de trabalho, proceder a estudos específicos, definir os EPIs adequados, manter relacionamento com a CIPA (ver abaixo), realizar projetos e estatísticas para atuar sobre os pontos prioritários e assumir as responsabilidades das atividades do SESMT, nunca esquecendo que os profissionais respondem por seus atos sob todos os aspectos legais. 


\section{Comissão interna de prevenção de acidentes (CIPA)}

A NR-5 disciplina a CIPA, que possui como escopo fundamental a prevenção de acidentes. Trata-se de um órgão da empresa, cuja constituição se dá de forma paritária, com representados apontados pelos empregadores, bem como os representantes eleitos pelos empregados. As empresas com mais de 20 funcionários, a depender do grau de risco e do número de empregados, deverão ter uma CIPA, que possui como uma de suas atribuições a garantia da segurança no interior das empresas (Proscurcin, 2015).

\section{Programa de Controle Médico e Saúde Ocupacional (PCMSO) \\ Diante das premissas}

constitucionais e legais atinentes ao meio ambiente do trabalho, não se pode olvidar que a pretensão pela redução de riscos em determinada série laboral, favorecem à proteção à integridade física, bem como à vida do trabalhador.

A estruturação desse programa está fincada na NR-7, e possui como finalidade o combate à degradação do ambiente de trabalho, com enfoque na prevenção e deteç̧ão de problemas na saúde do trabalhador, de patologias decorrentes das próprias condições de labor do indivíduo. É de se suscitar que um dos pontos mais importantes desse programa, revela na obrigatoriedade da realização de exames médicos, com o fito de detectar possíveis doenças ocupacionais, no que será possível realizar um acompanhamento minucioso da saúde do trabalhador, nas condições e locais de trabalho a que está inserido (Proscurcin, 2015).

Nesta monta, a adoção de medidas que favoreçam e possibilitem a preservação da saúde dos trabalhadores, cumpre determinação contida na referida norma regulamentar, pela qual resta o dever, por parte dos empregadores, de elaborar e implementar o PCMSO, configurando-o como medida preventiva à saúde do trabalhador, além de possibilitar a verificação de possíveis doenças profissionais ou de eventuais danos irreversíveis acometidos à saúde dos empregados (Sturme, 2016).

Assim, esses programas representam ferramentas de controle e prevenção à saúde do trabalhador, como forma de deferência à preservação por um meio de ambiente do trabalho saudável à saúde humana (Sturme, 2016).

0 PCMSO descreve as responsabilidades e competências do empregador, in verbis:

Norma Regulamentar no 07:

[...]

7.3 DAS RESPONSABILIDADES

7.3.1 Compete ao empregador:

a) garantir a elaboração e efetiva implementação do PCMSO, bem como zelar pela sua eficácia;

b) custear sem ônus para o empregado todos os procedimentos relacionados ao PCMSO; (Alterada pela Portaria no 8, de 5 de maio de 1996)

c) indicar, dentre os médicos dos Serviços Especializados em Engenharia de Segurança e Medicina do Trabalho - SESMT, da empresa, um coordenador responsável pela execução do PCMSO;

d) no caso de a empresa estar desobrigada de manter médico do trabalho, de acordo com a NR no 04 , deverá o empregador indicar médico do trabalho, empregado ou não da empresa, para coordenar o PCMSO;

e) inexistindo médico do trabalho na localidade, o empregador poderá contratar médico de outra especialidade para coordenar o PCMSO.

Diante da norma regulamentar, ao empregador incubem a responsabilidade pela confecção e execução do PCMSO, além de tantas outras responsabilidades decorrentes da própria norma regulamentar, com o fito de promover a eficácia do plano (Sturme, 2016). 


\section{Conclusão}

0 meio ambiente do trabalho carreia uma definição de conteúdo que vem sendo enriquecido paulatinamente no curso da história, através dos desafíos apresentados pelo tempo. Em seus primórdios, sua conceituação estava vinculada à saúde pública, da qual foi-se desvinculando a partir da construção da noção de saúde ocupacional e do reconhecimento do trabalho como um elemento originador de patologias específicas.

Segundo classificação internacional, assimilada pela legislação de diversos países, vislumbra-se, ainda, uma dependência dos instrumentos de proteção à saúde do trabalhador bem como dos estudos relacionados à saúde pública, cujos resultados certamente trazem avanços epistemológicos acerca da saúde do trabalhador. Neste interim, doenças como depressão, estresse e ansiedade têm a sua gênese relacionada ao meio ambiente do trabalho pelos profissionais de saúde pública.

A legislação atinente ao meio ambiente do trabalho, ainda possui traços arraigados a aspectos unidimensionais à saúde do trabalhador. Indubitavelmente, é o reflexo de uma legislação inspirada no modelo industrial de produção, no qual os danos físicos se sobrepõem aos danos psíquicos, de sorte que tal realidade, não responde aos anseios hodiernos, no qual o trabalho manual vem sendo paulatinamente substituído pelas atividades que envolvam relações interpessoais e cada vez mais, o intelecto humano, com o consequente aumento de doenças psíquicas e mentais, originados pela prática crescente e contumaz de assédio moral, assédio sexual, pressão, temor pela perda do emprego etc.

A matéria possui uma enorme variabilidade legiferante, no que pertine às normas que se debruçam sobre o meio ambiente do trabalho, além de mecanismos processuais para a sua tutela, que favorecem a sistematização da tutela do meio ambiente do trabalho.

Por último, conquanto o meio ambiente do trabalho seja considerado um meio ambiente artificial especial, espécie do gênero meio ambiente, seus fundamentos necessitam de uma construção que apresente maior concatenação com os princípios gerais do meio ambiente, como os princípios da prevenção, da precaução, do desenvolvimento sustentável, do poluidor-pagador, da participação e da ubiquidade, para que as condições de trabalho possam garantir um desenvolvimento integral desse direito fundamental do trabalhador.

\section{Conflito de interesses}

Os autores declaram não haver conflito de interesses.

\section{Referências}

Araujo Junior, F. M. Doença ocupacional e acidente de trabalho: análise multidisciplinar. São Paulo: LTr, 2009.

Brandão, C. Meio ambiente do trabalho saudável: direito fundamental do trabalhador. Meio Ambiente do Trabalho Aplicado, p. 220-237, 2016. Disponível em: <http://vlex.com/vid/vel-direitofundamental-trabalhador-520429862>. Acesso em: 23 abr. 2018.

Brasil. Constituição da República Federativa do Brasil de 1988. Disponível em: <http://www.planalto.gov.br/ccivil_03/ Constituicao/Constituicao.htm>. Acesso em: 23 abr. 2018.

Brasil. STF. V. ADI 3540 MC, Relator: Min. Celso de Mello, Tribunal Pleno, julgado em 10.9.2005, DJ 3.2.2006 p. 14 Ement v. 221903 p. 528.

Canotilho, J. J. G. Estudos sobre direitos fundamentais. 2. ed. Coimbra: Coimbra, 2008.

Durkheim, E. The division of labour in society. Glencoe, IL: Free Press., 1964.

Engels, F. The condition of the English working class in England. St Albans: Granada, 1969. 
Gomes, H. Medicina legal. 33. ed. Rio de Janeiro: Freitas Bastos, 2005.

Figueiredo, T. M. C.; Gondim, K. M. L. O direito a um meio ambiente do trabalho equilibrado e a ineficácia dos instrumentos protetivos atualmente adotados. Revista Trabalhista, Direito e Processo, n. 53, p. 90-102, 2015. Disponível em: <http://vlex.com/vid/direitoum-meio-ambiente-583291030>. Acesso em: 22 jun. 2018.

Penteado Filho, N.S. Manual de Direitos Humanos. São Paulo: Método, 2008.

Jorge Neto, F. F.; Cavalcante, J. Q. P. Manual de Direito do Trabalho. Rio de Janeiro: Lumen Juris, 2004. Tomo II.

Leal, R. G. A quem compete o dever de saúde no direito brasileiro? Esgotamento de um modelo institucional. Revista de Direito Sanitário, v. 9, n. 1, p. 50-69, 2008. https://doi.org/10.11606/issn.2316-9044. v9i1p50-69

Marx, K. Capital: A critique of political economy. Harmondsworth: Peguin, 1981.

Melo, R.S. Meio ambiente do trabalho: prevenção e reparação - juízo competente. Juris Síntese IOB, São Paulo: IOB, 2007. CD-ROM.

Moraes, A. Direitos Humanos Fundamentais. São Paulo: Atlas, 1997.

OIT - Organização Internacional do Trabalho. Piores formas de trabalho infantil: um guia para jornalistas. OIT, 2010. Disponível em: <http://www.oit.org>. Acesso em: 07 jun. 2018.

Prata, M. R. 0 meio ambiente do trabalho e a constituição. Revista Vlex Brasil, p. 177-229, 2016. Disponível em: <http://vlex.com/vid/ meio-ambiente-do-trabalho-constituia496426282>. Acesso em: 07 jun. 2018.
Proscurcin, P. Compêndio de Direito do Trabalho: introdução às relações de trabalho. São Paulo: LTr, 2016.

Santos, B.S. Para uma concepção multicultural dos Direitos Humanos. Revista Crítica de Ciências Sociais, n. 48, 1997. Disponível em: <http://www.boaventurade sousasantos.pt/media/pdfs/Concepcao_mult icultural_direitos_humanos_ContextoInternac ional01.PDF>. Acesso em: 25. jun. 2018.

Santos, R. L. Evolução histórico-normativa da tutela jurídica do meio ambiente do trabalho e instrumentos de proteção. Meio Ambiente do Trabalho Aplicado, p. 220-237, 2016. Disponível em: <http://vlex.com/vid/ normativa-tutela-jura-dicainstrumentos20429998>. Acesso em: 07 jun. 2018.

Sturme, G. Direitos Humanos e meio ambiente do trabalho. Veredas do Direito, v. 13 n. 25 p. $155-172,2015$.

Sturme, G. O trabalho, o direito do trabalho e o Protocolo de San Salvador. Revista de Estudos Constitucionais, Hermenêutica e Teoria do Direito, v. 6, n. 1, 2014.

Trennepohl, T. D. Fundamentos de Direito Ambiental. 2. ed. Salvador: Juspodium, 2007. Trigueiro, C. S. Discriminação por graus de deficiência: o caso das súmulas do STJ para visão monocular e surdez unilateral. Rio de Janeiro: Lumen Juris, 2017. 